\title{
A transexualidade e 0 estranhamento do corpo: sobre os recursos à mudança de sexo
}

\author{
Luciana Ribeiro Marques \\ Gisele Lavinas \\ Vinicius Müller
}

\begin{abstract}
Resumo
O presente trabalho visa a apresentar alguns fragmentos do documentário produzido a partir da pesquisa de Iniciação Científica "A transexualidade e o estranhamento do corpo", que conta com o apoio do Programa Institucional de Bolsas de Iniciação Científica, e as possíveis articulações com a psicanálise no que tange aos discursos sobre o estranhamento do corpo, aos recursos à mudança de sexo, à escolha do parceiro e à representação do que é ser homem e do que é ser mulher.
\end{abstract}

\section{Palavras-chave:}

Sexualidade; Transexualidade; Corpo; Semblante.

\section{Transsexuality and body estrangement: on the resources of sex change}

\begin{abstract}
This work aims to present some fragments of the documentary produced from the Undergraduate Research "Transsexuality and body strangeness" - which counts on the support of the Institutional Program of Undergraduate Research Scholarships - and the possible correlations with psychoanalysis, in reference to sex change, choice of partners and representation of what it means to be a man or a woman.
\end{abstract}

Keywords:

Sexuality; Transsexuality; Body; Semblant. 


\title{
La transexualidad y el extrañamiento del cuerpo: sobre los recursos para cambiar el sexo
}

\begin{abstract}
Resumen
El presente trabajo pretende presentar algunos fragmentos del documental producido a partir de la Investigación de la Iniciación Científica de la transexualidad y el alejamiento del cuerpo - que cuenta con el apoyo del Programa Institucional de Becas de Iniciación Científica - y las posibles articulaciones con el psicoanálisis, en cuanto a los discursos sobre el extrañamiento del cuerpo, los recursos para el cambio de sexo, la elección del compañero y la representación de lo que es ser un hombre y lo que es ser una mujer.
\end{abstract}

\section{Palabras clave:}

Sexualidad; Transexualidad; Cuerpo; Semblante.

\section{La transsexualité et la répulsion du corps: à propos des ressources pour changer le sexe}

\begin{abstract}
Résumé
Le présent travail vise à présenter certains fragments du documentaire produit à partir de la Recherche de l'Initiation Scientifique de la transsexualité et l'éloignement du corps - qui compte avec le soutien du Programme Institutionnel de Bourses d'Initiation Scientifique - et le possible articulations avec la psychanalyse, en ce qui concerne les discours sur l'éloignement du corps, les ressources pour le changement de sexe, le choix du partenaire et la représentation de ce qui est d'être un homme et de ce qui est d'être une femme.
\end{abstract}

\section{Mots-clés:}

Sexualité; Transsexualité; Corps; Semblant.

O fenômeno da transexualidade, que não data de hoje, ganha relevo na atualidade pela oferta de hormonioterapia, cirurgias reparativas e redesignação sexual. Com a oferta, surge a demanda, e é aí que os transexuais padecem de um erro, “(...) que é justamente o erro comum. Sua paixão, a do transexual, é a loucura de querer livrar-se desse erro (...)" (Lacan, 1971-1972/2012, p. 17); pois, diante da aposta de conformação entre a aparência do corpo e o sexo com que se identificam, "é como significante que o transexual não o quer mais [ou o reivindica], e não como órgão” (Lacan, 1971-1972/2012, p. 17). Decerto que o pênis, suporte 
imaginário do falo, tem função operativa nesse processo, funcionando para o ser de linguagem como o objeto do desejo no nível do ter, uma vez que é o único órgão do corpo capaz de orientar o sujeito: desejo confesso com a ereção e ausente com a detumescência. Assim, a recusa do pênis por parte do transexual se revela como uma recusa à ereção do pênis, pela qual o desejo do homem se presentifica. Com a reivindicação do pênis não é diferente, embora não resolva a questão, pois a prótese peniana não substitui o órgão do desejo, uma vez que não é capaz das propriedades mágicas que esse órgão revela. $O$ fato é que, embora a oferta de recursos cirúrgicos vise a atrelar corpo e gênero, prometendo um encontro harmônico do sujeito com seu sexo, na sexualidade há um real em jogo que não é simbolizado, permanecendo indizível.

Portanto, pertencer a um sexo é uma questão significante, uma vez que o falo, como operador lógico da diferença dos sexos, ratifica que $\mathrm{O}$ Homem é um mítico Totem e que $\mathbb{A}$ mulher não existe. Ao homem, apoiado em seu atributo fálico - que nada lhe garante, embora sentencie a lógica do ter —, resta sustentar-se como pura aparência, um parecer-homem, sustentação de uma fachada, como nos diz Lacan. Daí, não importa se nessa fachada o semblante é ora masculino, ora feminino, ou se a escolha de objeto é heterossexual ou homossexual. O fato é que, como homem, seu gozo é limitado ao gozo fálico, uma vez que O Homem, o Todo-Homem, só existe como proposição universal, como significação produzida por efeito de discurso: um Totem. Com as mulheres, também há uma impossibilidade. Pela falta de referente do ideal feminino, não há qualquer chance de identificação com a mulher, restando como única identificação possível - tanto para os homens quanto para as mulheres - a identificação fálica; seja por intermédio do pai ou da mãe que, por sua função, é fálica. Por isso Lacan afirma, de saída, que $\mathbb{A}$ mulher não existe, uma vez que não há representação de seu sexo no inconsciente, de onde deriva a barra que incide sobre o que seria A: "não há referência possível à mulher, porque não há a mulher universalmente” (Lacan, 1975/1994, p. 132), representando, então, a alteridade absoluta para ambos os sexos.

Com o intuito de pensarmos a transexualidade, o estranhamento do corpo e os recursos à mudança de sexo, selecionamos seis depoimentos - três transmulheres e três trans-homens, extraídos do documentário A transexualidade e o estranhamento do corpo, em produção desde 2016 e parcialmente apresentado no II Simpósio Interamericano da Internacional dos Fóruns: Sexuação e Identidades. Com a transcrição de parte do recurso audiovisual produzido pela pesquisa de iniciação científica, pretendemos abarcar a sexualidade em seu aspecto de criação, um saber fazer com o real, pois não é isso! "(...) grito por onde se distingue o gozo obtido do gozo esperado" (Lacan, 1972-1973/1985, p. 152), impossibilidade, inadequação, produtora do mal-estar, inerente ao ser de fala. 


\section{O estranhamento do corpo}

Dandara Vital: "Na verdade, eu demorei para me identificar como mulher-trans. Eu sempre achei que eu fosse um homem gay. A primeira coisa que me incomodou foram os pelos... porque a minha mãe, ela é... o apelido dela é pelada, porque ela quase não tem pelo. As feições masculinas eram coisas que me incomodavam, mas a coisa que mais me incomodava era o pelo."

Fabiana Tanigucci Gondo:" "Sempre uma sensação de que tinha algo errado, sempre uma sensação de não estar completa... bastante dividida, sem saber como resolver essa incongruência entre a minha mente e o meu corpo. Sempre houve uma preocupação minha em não deixar transparecer para não decepcionar meus pais.”

Patrícia:3 "Desde quando eu era criança, uns 3 anos de idade, eu já não me sentia bem com o meu corpo. Eu sentia umas coisas estranhas, via que era diferente das outras pessoas. Eu sempre andava com roupas escondendo o meu corpo, sempre andava com roupa abaixo do joelho e blusas de manga longa... eu usava casaco por não gostar do meu corpo e querer esconder."

Johi:: "Eu descobri que eu era um transexual já com 20 anos de idade, demorou um pouco. Mas, antes disso, eu nunca me identifiquei com o feminino... na verdade, eu me via perdido... eu não sabia como ia viver assim, eu só vivi... sobrevivi."

Leonard: "Eu costumo dizer que eu nasci menino, mas, pela sociedade, se você nasce com uma vagina, é taxado como mulher... Vivi a minha vida inteira como 'lésbica', entendeu? Só que eu sentia que estava faltando alguma coisa na minha vida. Então... eu conheci uma ex minha que me ajudou... me mostrou os transgêneros nos EUA... e, quando eu olhei uma foto, falei: É isso! Eu vi o corpo, né? Assim, falei: é isso que eu quero."

Yuri Branco: " "Existe uma diferença entre quando eu sei exatamente o que está acontecendo para desde quando eu me sinto dessa forma. Eu sempre fui uma criança diferente. Nasci mulher, biologicamente, e quando era criança eu sempre era meio que confundido com menino... minha mãe fala bastante sobre isso, essa questão de como eu criança já apresentava isso, desde bebê. Tanto que ela achava que eu nasceria biologicamente homem, desde sempre."

A diferença anatômica entre os homens e as mulheres e o resultante estranhamento do corpo denunciado pelos transexuais apontam para o mal-estar produzido pela linguagem. Com os seis fragmentos aqui descritos, podemos verificar

1 Dandara Vital (mulher-trans), 36 anos, atriz.

2 Fabiana Tanigucci Gondo (mulher-trans), 40 anos, servidora pública.

3 Patrícia (mulher-trans), 21 anos, maquiadora.

4 Johi (homem-trans), 24 anos, bartender.

5 Leonard (homem-trans), 37 anos, estudante universitário.

6 Yuri Branco (homem-trans), 23 anos, estudante universitário. 
que o mistério do corpo é o real, aquilo que do corpo falante, impregnado pela linguagem e marcado pelo inconsciente, escapa da completa apreensão. O Outro, discurso que precede o sujeito, modelador da criança no simbólico, impregna pela fala, produzindo efeitos inclusive pelo que escapa à emissão; contingência entre o que é enunciado pelo Outro e o que é recebido pela criança: o desejo. É desse modo que a estrutura de linguagem engaja o corpo, produzindo a singularidade. Trata-se das marcas significantes, que comportam o fora de sentido de alíngua, e da fantasia, erigida pelo sujeito diante do enigma do desejo do Outro. Desde então, diante de toda elucubração possível ao sujeito, do corpo, ele só sabe um pedaço, tal como Colette Soler adverte, objetando o ideal da transmissão integral vislumbrada pela ciência: "o mistério do corpo falante é o mistério do corpo marcado, afetado pelo saber da alíngua do sujeito e, de forma sempre singular, jamais completamente apreensível" (Soler, 2010, p. 29).

Sem dúvida, o corpo que sustenta nossa pesquisa - falante, pulsional e inapreensível por completo - não é o mesmo que ancora a patologização da transexualidade promovida pelas ciências médicas por meio do Manual de classificação de transtornos mentais e do comportamento, do CID-10, e do Manual diagnóstico e estatístico de transtornos mentais (DSM). Foi em 1952 que a Associação Psiquiátrica Americana (APA) lançou seu primeiro DSM, incluindo, na mesma rubrica da homossexualidade, da pedofilia, do fetichismo e do sadismo sexual, o travestismo, termo que abarcava todo e qualquer sujeito que se utilizasse de acessórios ou trejeitos socialmente apontados como pertencentes ao possuidor do sexo anatômico oposto. Nesse momento, o termo transexualidade ainda não existia, mas a anatomia do corpo já alicerçava o manual de normas de conduta a serem praticadas, reduzindo o sujeito à categoria do travestismo, “(...) principalmente, em termos de sociedade e de conformidade com o meio cultural prevalecente, e não apenas em termos de desconforto pessoal e relações com outros indivíduos" (APA, 1952, pp. 38-39). Sem dúvida, uma classificação que anula o sujeito em sua singularidade em prol da moral sexual normativa; ancoragem que permaneceu por 16 anos, até que, em 1968, com o lançamento do DSM-2, separou-se a classificação de comportamentos referentes à identidade de gênero dos comportamentos concernentes à escolha do parceiro.

Embora a homossexualidade e o travestismo tenham recebido rubricas diferentes, a descrição do travestismo permanecia associando essas duas escolhas:

Esta categoria é para indivíduos cujos interesses sexuais são direcionados primariamente para objetos que não sejam pessoas do sexo oposto, em direção a atos sexuais geralmente não associados ao coitus, ou ao coito realizado em circunstâncias bizarras como na necrofilia, na pedofilia, no sadismo sexual e no fetichismo. (APA, 1968, p. 44) 
A transexualidade, como fenômeno derivado de uma identidade psíquica que diverge da anatomia do corpo, classificada como transtorno psicossexual, surge em 1980, ao ser lançado o DSM-3. O transexualismo, caracterizado como um transtorno heterogêneo, abarca o item 302.5x do manual diagnóstico, cujas características essenciais são:

Um sentido persistente de desconforto e inadequação sobre o sexo anatômico, um desejo persistente de se livrar dos órgãos genitais para viver como um membro do outro sexo. O diagnóstico é feito somente se o distúrbio for contínuo (...) por pelo menos dois anos. (APA, 1980, pp. 261-262)

Dez anos depois, surge um novo manual classificatório para as ciências médicas, o CID-10. A transexualidade configura a categoria F64.0 - Transexualismo - e é classificada como um transtorno de identidade sexual (F64), pertencente à categoria Transtorno de Personalidade e de Comportamento em Adultos (F60-F69), definida de modo muito semelhante à presente no DSM-3. Desde então, o DSM se vê obrigado a passar por uma atualização e, 14 anos após sua última edição, lança, em 1994, o DSM-4. A transexualidade migra da classificação de Transtornos Psicossexuais e passa a ser categorizada como um Transtorno de Identidade de Gênero, descrito a partir de quatro critérios:

Deve haver evidências de uma forte e persistente identificação com o gênero oposto (...) (Critério A). Esta identificação (...) não deve refletir um mero desejo de quaisquer vantagens culturais percebidas por ser do outro sexo (...) (Critério B). O diagnóstico não é feito se o indivíduo tem uma condição intersexual física concomitante (...) (Critério C). Para que este diagnóstico seja feito, deve haver evidências de sofrimento clinicamente significativo ou prejuízo no funcionamento social ou ocupacional ou em outras áreas importantes da vida do indivíduo (Critério D). (APA, 1994/1995, p. 504)

Assim, pela primeira vez, faz-se menção à necessidade de escuta do sujeito diante de seu sofrimento psíquico, embora mantenha-se a transexualidade como um fenômeno característico de desordem mental, arranjo que varia em relação à nomenclatura, mas que se mantém até hoje. Recentemente, em 2013, surge a mais nova versão desse compêndio, o DSM-5, e o Transtorno de Identidade de Gênero é, então, substituído pela Disforia de Gênero, dando relevo à Disforia “(...) como um problema clínico, e não como identidade por si própria” (APA, 2013/2014, p. 452). Esse dito problema clínico faz referência “(...) ao sofrimento que pode acompanhar a incongruência entre o gênero experimentado ou expresso e o gênero designado de uma pessoa" (APA, 2013/2014, pp. 451-452), acrescentando que, 
“embora essa incongruência não cause desconforto em todos os indivíduos, muitos acabam sofrendo se as intervenções físicas desejadas por meio de hormônios e/ou de cirurgia não estão disponíveis” (APA, 2013/2014, p. 452). A transexualidade, agora classificada como Transtorno do Desenvolvimento Sexual, mantém a escolha do sujeito diante de seu sexo como fator secundário à categorização do manual classificatório, que permanece reduzindo o sujeito e seu sofrimento a dados estatísticos e mensuráveis, compendiados em critérios. Contudo, o fato que merece destaque é a atual classificação de disforia, que, ao manter a transexualidade como transtorno categorizado nos manuais psiquiátricos, gera a garantia do processo transexualizador, tão almejado pelos transexuais. Ou seja, a oferta de hormonioterapia, de cirurgias reparadoras e de redesignação sexual são as responsáveis pela manutenção do transtorno, conservando a transexualidade nos manuais psiquiátricos, ponto que nos leva à nossa segunda questão: os recursos à mudança de sexo.

\section{Os recursos à mudança de sexo}

Dandara Vital: "Na verdade eu me atraquei nos hormônios por conta própria. Loucura! Eu comecei com 23, 24 anos. Mas eu comecei a me vestir mesmo, assim, de forma feminina, a me maquiar, que eram coisas que eu já queria fazer há algum tempinho, quando me olhei no espelho e vi realmente o que queria ver. Eu fiz uso de silicone industrial, né? Botei na minha casa com uma bombadeira. Coloquei no peito e no quadril."

Fabiana Tanigucci Gondo: "Roupas da mãe, roupas da prima... e depois, com mais idade, deixei o cabelo crescer. Até chegar à idade adulta, eu só explorava dessa forma, nunca tive coragem de ultrapassar esses limites, sempre tudo escondido... e sempre com certa culpa. Fiz uma cirurgia na face, um corte, uma diminuição do ângulo da mandíbula... deixando o rosto mais feminino. A outra intervenção foi um preenchimento na região das bochechas, que deu uma delicadeza ao rosto, depois veio o corpo, implante nos seios e abdominoplastia. Por último, a cirurgia de transgenitalização, que eu fiz na Tailândia. Eu tenho que ser sincera, porque eu ainda não experimentei... ainda não estou plenamente recuperada e ainda não experimentei, digamos, a nova aparelhagem.”

Patrícia: "A primeira vez que tomei hormônio tinha 15 anos. Comecei a tomar por conta própria mesmo... eu me sentia diferente de todo mundo da minha família, me sentia estranha, como se tivesse duas almas dentro de mim, mas só que não era isso, era a alma que não correspondia ao corpo. Quando ficava excitada, dava vontade de cortar fora. Eu não gostava de ficar excitada, me irritava, ficava com muita raiva mesmo, incomodava muito, ao ponto de, sei lá, atrapalhava minha vida. Muito estranho isso, até hoje não me acostumo... parece que você está preso. É você ficar preso num corpo que não é seu. É praticamente isso, você está numa prisão, por não saber o que fez." 
Johi: "Até os meus 11 anos de idade, eu usava roupas do meu irmão ou ficava sem camisa. Só na adolescência, que começou a formar corpo, que minha mãe começou a me cobrar para que eu não usasse mais as roupas do meu irmão, e eu tentava usar uma roupa feminina... Eu costumo dizer que me senti traído pelo meu corpo. Eu me sentia vulgar, me sentia sujo, estranho, e não me olhava no espelho, não me olhava mesmo. Em partes foi resolvido, porque eu fiz a mastectomia masculinizadora... foi uma liberdade para mim... porque era um lugar onde a gente usava faixa e tal, então prende, machuca o corpo, e eu fiquei com problema de saúde. Além de que, comecei a ter fobia social... achar que as pessoas estavam me olhando. Eu já fui seguido dentro do mercado, no início da transição, e em vários lugares. Mas, em relação ao genital, infelizmente, eu tenho que aceitar ainda o que tem, porque a cirurgia aqui é impossível. No Brasil, é muito complicado, não é satisfatório o resultado. Diferente das mulheres-trans, que já está liberado. Por mim, eu faria todas as cirurgias."

Leonard: "Quando você olha no espelho e você fala assim: pô, não estou no meu corpo! Eu costumo dizer que adequei tudo que estava na minha cabeça, comecei a fazer o tratamento hormonal. O genital, para mim, nunca foi problema. Não, nunca foi nada... com o genital, nada, nada. É o órgão que a gente nasce, entendeu?"

Yuri Branco: "No início, eu tinha muito... acho que não é repulsa, mas eu não aceitava muito bem. Acho que é uma questão muito pessoal... como você se sente com seu órgão, né? Eu não tenho vontade de fazer a cirurgia, mas já tive. Eu vejo que o ser humano é muito mais do que seu órgão genital. Eu sou homem, e independente do que eu tenha ou não. Faço terapia hormonal tem três anos mais ou menos. Eu só fiz a cirurgia dos seios. Não senti vontade de fazer nenhuma outra.”

Conforme podemos observar nos relatos extraídos do documentário, há uma fronteira que se delimita entre alguns transexuais, que, embora ratifiquem o estranhamento com o corpo, desejam manter o órgão genital biológico, enquanto outros vislumbram, como único recurso diante do estranhamento, a submissão à cirurgia de redesignação sexual. Na maioria dos casos, os reparos estéticos e o uso de hormônios são os recursos usados pelos transexuais que não visam à cirurgia de transgenitalização. Eles também modificam seu corpo a fim de conformá-lo à aparência do sexo com que se identificam, mas, mesmo havendo a oferta da cirurgia, não há demanda, e eles mantêm o órgão sexual, sustentando seu gênero com o semblante, recurso possível ao humano. Entretanto, para outros, o estranhamento do corpo ultrapassa a possibilidade de se utilizar do recurso ao semblante e culmina na demanda cirúrgica genital como uma convicção. Nesses casos, as transmulheres recusam o órgão peniano e visam à sua extirpação, enquanto os trans-homens reivindicam a prótese peniana como um substituto do órgão do desejo.

Foi a partir dessa constatação, ancorada nos manuais psiquiátricos que classificam a disforia de gênero como um Transtorno do Desenvolvimento Sexual e vislumbram as intervenções físicas como única saída diante do sofrimento psíquico, 
que o Sistema Único de Saúde (SUS) pôde definir, em agosto de 2008, por meio das Portarias no 1.707 e no 457 , as Diretrizes Nacionais para o Processo Transexualizador no Brasil. Visando à redução do sofrimento dos transexuais, passou a garantir o uso do nome social, da hormonioterapia e do acesso à cirurgia de adequação do corpo à identidade de gênero e social. Desde novembro de 2013, pela Portaria no 2.803, a Secretaria de Atenção à Saúde redefiniu e ampliou essas Diretrizes. A partir de então, cabe ao Ministério da Saúde garantir que todos os procedimentos médicos necessários sejam realizados pelo SUS. ${ }^{7}$

Diante da proposta do SUS, o que vale destacar, com Lacan, é que a subjetivação do sexo é um efeito do enodamento dos registros real, simbólico e imaginário, provenientes do processo de constituição do sujeito. Essa amarração permite ao ser humano sustentar o parecer homem ou o parecer mulher, sejam eles transexuais ou não, uma vez que "no psiquismo não há nada pelo que o sujeito pudesse se situar como ser de macho ou ser de fêmea. (...) o que se deve fazer como homem ou como mulher, o ser humano tem sempre que aprender, peça por peça, do Outro" (Lacan, 1964/1998, p. 194), com a linguagem. Daí alguns transexuais dispensarem a intervenção cirúrgica genital como quarto elemento desse nó, que Freud chamou "realidade psíquica", ou mais conhecido como "(...) complexo de Édipo. Sem o complexo de Édipo, nada da maneira como ele se atém à corda do Simbólico, do Imaginário e do Real se sustenta" (Lacan, 1974-1975, p. 18, inédito). Logo, é a partir do Édipo, tal como Lacan esclarece, que se apresenta a função do semblante do sexo, por meio das identificações com os pais, Outros primordiais que desenham, pela linguagem, os significantes, o que se pode dizer do homem e da mulher: "não há relação sexual". Desse modo, podemos pensar que, apenas quando a realidade psíquica do sujeito requer um quarto elemento que sustente as cordas desse nó edípico - promovendo um enodamento possível ao RSI - , a cirurgia de transgenitalização torna-se requisito à conformação entre o corpo e a identidade psíquica?

7 Acompanhamento mensal do usuário no processo transexualizador pré e pós-operatório; terapia medicamentosa hormonal; redesignação sexual no sexo masculino com orquiectomia bilateral (remoção cirúrgica dos testículos) com amputação do pênis e neocolpoplastia (construção de neovagina), tireoplastia (cirurgia de redução do pomo de adão com vistas à feminilização da voz e/ou alongamento das cordas vocais), tratamento hormonal preparatório para cirurgia de redesignação sexual; mastectomia simples bilateral (ressecção de ambas as mamas com reposicionamento do complexo aréolo-mamilar), histerectomia (remoção do útero) com anexectomia (remoção das trompas de falópio e dos ovários) e colpectomia (remoção da vagina); plástica mamária reconstrutiva bilateral, incluindo prótese mamária de silicone; atendimento clínico realizado por equipe multiprofissional e cirurgias complementares. 
Conforme verificamos anteriormente, no nível do discurso, o corpo assimila as relações simbólicas e imaginárias. No nível simbólico, o significante marca o corpo e, pela linguagem, dá corpo ao sujeito, inscrevendo-se pela representação inconsciente que a anatomia desconhece, mas que o leva a perceber a consistência real do organismo, órgãos e funções que a linguagem isola. Já no nível imaginário, o organismo despedaçado dá lugar à consistência da forma, promovendo o sentimento de unidade e de pertencimento que leva Freud a afirmar, no texto sobre o narcisismo (Freud, 1914/2012), que a imagem será tomada como objeto de amor e investimento libidinal privilegiada pelo sujeito. Desse modo, diante de um corpo que é tríplice - simbólico, imaginário e real —, seria possível conjecturar, para além de um quarto nó edípico, a discordância entre o hábito requerido ao corpo domesticado e o sentimento que se tem dele?

É necessário que se leve bem em conta que existe uma fábrica do corpo, de nossos corpos socializados. (...) E é certo que a educação (...) é uma tentativa de domar o corpo, de fazê-lo entrar nas práticas corporais coletivizantes. (...) Há toda uma transmissão de posturas socializadas admissíveis. E, para entrar nos bons costumes, nós os fazemos se curvarem aos hábitos. (Soler, 2010, p. 37)

Certa indução de modelos que pode reduzir o corpo a seu mau funcionamento, erogeneização fora de lugar que acaba por tentar domesticar a função fálica e ratificar o ajuste genital como única saída possível para o corpo objetor ao funcionamento do discurso coletivo, regulação de gozo que culmina na intervenção física proposta pelos manuais diagnósticos, visando, inclusive, à adequação do corpo a corpo, terceiro ponto abordado em nossa pesquisa: a escolha do parceiro.

\section{A escolha do parceiro}

Dandara Vital: "Me considero heterossexual. Ele [O namorado atual] é um homem-trans... Já tinha beijado outros, mas nunca tinha transado. E os outros dois que eu beijei... não foi tão interessante. Aí, com o meu namorado, a primeira vez que a gente se beijou já deu a química."

Fabiana Tanigucci Gondo: "Sempre a atração... a minha orientação... sempre foi lésbica, vamos dizer assim, minha identidade de gênero sempre foi feminina, $e$ minha atração sempre foi dirigida ao sexo feminino."

Patrícia: "Heterossexual. Com 12 anos... foi com meu primo mesmo. Eu me sentia desconfortável em relação ao órgão sexual, entendeu? De ficar do jeito que ficava. Só que eu já gostava desse tipo de coisa... só com meninos, entendeu? Por meninas eu nunca senti atração.” 
Johi: "Eu me considero pansexual... as pessoas têm mania de chegar e querer perguntar o que a pessoa tem no meio das pernas, sabe? A pansexualidade não tem isso. Eu não me interesso sexualmente por homens, só por mulheres, independente de ser uma mulher-cis ou uma mulher-trans ou uma travesti. A minha namorada é um travesti."

Leonard: "Minha namorada é uma mulher. Ela é cisgênero. Eu me considero pansexual. A pessoa que me faz bem, me faz feliz e eu gosto da pessoa, é isso. Antes dela, eu estava com um relacionamento com um menino gay, entendeu? Ele era cisgênero também... é indiferente."

Yuri: "Mulher, sempre. Eu sempre me relacionei com mulheres. Então... sou hétero, heterossexual, né? Eu sempre gostei de mulheres e nunca tive nada com homem.”

Com Freud, sabemos que a escolha do parceiro, seja homo ou heterossexual, é inconsciente e se dá em dois tempos: a escolha primária, edípica, e a consequente escolha aloerótica na vida adulta. A corrente afetiva edípica corresponde à escolha de objeto primária da criança, por onde a afeição aos pais não exclui a natureza erótica dessa relação, uma vez que, com a contribuição das pulsões sexuais, a criança é tomada como objeto erótico de seus cuidadores. No entanto, com a elisão desse romance primordial, a partir do obstáculo instaurado pela barreira contra o incesto, as fixações afetivas permanecem e ajudam a conduzir o erotismo ao desvio de seus objetos sexuais originais; agora inadequados. Desse modo, o Édipo implica tanto a perda de gozo, a interdição quanto a eleição inconsciente do parceiro. Ou, dito de outro modo, não há primazia da pulsão genital, uma vez que a pulsão é o produto da incidência da linguagem no corpo, articulando os significantes com as zonas erógenas, pulsões parciais que ratificam o gozo solitário e limitado, em que dois não fazem um. Portanto, corpo e gozo são regulados pela linguagem e, embora os novos objetos da vida adulta sejam escolhidos com base nos traços dos objetos primordiais, no corpo a corpo não há relação sexual possível, pois só se chega à cópula pela linguagem: "os corpos copulam porque as palavras copulam no inconsciente, na linguagem. (...) Não há apenas obsessões, conversões, etc., o próprio casal, casal de gozo, é sintoma. Tanto no nível do gozo quanto no do parceiro eleito pelo inconsciente" (Soler, 2010, p. 35).

Daí Lacan afirmar que o sintoma faz suplência à carência resultante do fato de que a linguagem não inscreve o corpo a corpo de gozo. No nível sexual, o uso do corpo pelo sujeito tem um limite, e é esse o ponto que vale ser ressaltado, pois, "quando ousamos, como se faz todo dia, rotular nossos parceiros por seu sexo, é impressionante que tanto o homem quanto a mulher simulam [font semblant], cada qual nesse papel” (Lacan, 1971-1972/2012, p. 68). Logo, mesmo que o cenário seja traçado, mesmo que se faça do corpo um instrumento de prazer, não importa o sexo do parceiro, ele estará longe de assegurar uma resposta de gozo, 
uma vez que o desejo, embora oriente, conduz à visada da falha: "Eu insisti nisto, que o parceiro desse eu que é o sujeito, sujeito de qualquer frase de pedido é, não o Outro, mas o que vem se substituir a ele na forma de causa do desejo" (Lacan, 1972-1973/1985, p. 171), o que acaba por implicar, em todo ato sexual, a heterossexualidade, independente do sexo do parceiro escolhido, uma vez que, seja o sujeito homem ou mulher, o que está em jogo é o diferente, o parceiro como objeto

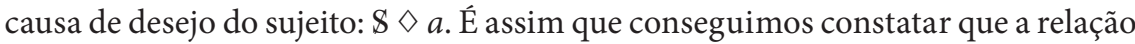
sexual entre o sujeito e o objeto que lhe causa é uma formação do inconsciente, uma fantasia, visto que o parceiro do sujeito não é tomado como outro sujeito, mas como objeto que, por meio de seus traços, traz a promessa de reencontro com o objeto primordial, perdido desde sempre. Disso se conclui que, independente de seu sexo, o parceiro será sempre um recorte, reduzido à dimensão de objeto por sua função de causa ao sujeito: "Quando se avança na direção desse vazio central, dado que é, até agora, sob essa forma que se apresenta para nós o acesso ao gozo, o corpo do próximo se despedaça” (Lacan, 1959-1960/1997, p. 246). Portanto, não importa se a escolha de objeto é hétero ou homossexual, como seres de linguagem, é mais com o falo $-\Phi-$ do que com o parceiro que nos relacionamos, seja no nível do ser ou do ter o falo. Ponto que nos conduz à quarta e última questão proposta neste artigo: $\mathrm{O}$ que é ser homem? O que é ser mulher?

\section{0 que é ser homem? 0 que é ser mulher?}

Dandara Vital: "A diferença... eu acho que é nos direitos. Ser mulher é muito mais difícil em relação a conquistar o seu espaço. Mas eu sou muito tradicional... acho que pela criação, religião rígida. Eu tenho muito essa coisa de que rosa é para a mulher e o azul é de homem... Eu sempre sofri preconceito por ser uma travesti, então não sei dizer se já sofri preconceito por ser mulher. É difícil responder essa diferença entre homem e mulher... estou buscando me desconstruir."

Fabiana Tanigucci Gondo: "É difícil... eu só consigo resolver isso de forma prática no meu dia a dia. Eu acho engraçado uma coisa, ser mulher te permite ser um pouco mais grossa com as pessoas. Quando você é um homem e discute com outro homem, existe sempre aquela possibilidade de um confronto físico. Então, os homens aprenderam a ter mais limites. Aí que eu descobri uma coisa: por que a mulher, em geral, é mais barraqueira? Porque esses limites com as mulheres não existem tanto assim. Comigo, eu nem sinto a questão da fragilidade, porque fisicamente eu não mudei, eu continuo grande, eu continuo faixa marrom de caratê... não me sinto mais frágil hoje em dia."

Patrícia: "Eu não sei o que é ser homem, entendeu? Porque é uma coisa que eu nunca fui. Eu só sei o que é ser mulher, e ser mulher é difícil. Ser uma mulher-trans, por outro lado, nem sempre tem os lados bons, é muita coisa que se passa, 
entendeu? Você não se aceitar no seu próprio corpo, esse tipo de coisa, e não se sentir bem com o corpo que tem."

Johi: "Acho que não tem diferença para mim... é uma questão de autoidentificação mesmo. Eu não gosto de destacar físico, aparência... isso não é nada... isso a gente muda, né?"

Leonard: "Ser homem ou ser mulher? Ser homem ou ser mulher? (...) É isso o que estava tentando lembrar... o ser homem é o quê? Eu viso o quê? O órgão genital, o pênis. Então, para ser homem, não precisa do órgão, entendeu? Ou para ser mulher... a identificação não precisa ser no órgão genital. Acho que ser homem é isso, e que ser mulher é isso."

Yuri: "Acho que é uma questão de sentir-se. Eu não consigo imaginar um ser homem, nem quando falam mulher eu consigo imaginar um ser tipo mulher. Acho que é uma questão de como a pessoa se sente e como ela se porta... eu não consigo imaginar um molde."

Sem dúvida, tanto o homem quanto a mulher existem, desde o princípio, como uma questão de linguagem; como valores sexuais que são aceitos em todas as línguas e que nos permitem dizer é ele ou é ela. No entanto, embora seja possível marcar essa distinção no nível do significante, escrevendo um $x$ para o significante homem e um $y$ para o significante mulher, não será a escrita desse $y$ que nos permitirá dizer o que seria distinto de $x$, justamente porque essa distinção é insuficiente para abarcar o que concerne de impasse sexual para os seres falantes. Retornemos a Freud a fim de verificar a abordagem das antíteses sexuais e o relevo à significação que se apresenta pela lógica da retroação, après-coup: em um primeiro momento, a oposição se dá entre sujeito e objeto, uma vez que o objeto está perdido desde sempre, restando a demanda ao Outro como reivindicação de algo que está separado dele. No momento seguinte, sádico anal, prevalece a oposição ativa e passiva, quando, diante da demanda do Outro, o sujeito trava uma luta entre o domínio e a submissão. Na primazia fálica, há masculino, mas não há feminino, uma vez que a oposição se dá entre os fálicos e os castrados. Assim, só na época da puberdade a antítese sexual coincide com masculino e feminino, efeitos de sentido derivados da impossibilidade de representação d'A Mulher no inconsciente. ${ }^{8}$

As antíteses sexuais, descritas por Freud, surgem de um processo lógico que parte da universalização do traço fálico. A hipótese freudiana destaca a universalidade do falo a partir de sua teoria da libido - única, masculina —, que se faz representar como fantasia infantil advinda do gozo do órgão. A atividade masturbatória, com sua inerente promoção de prazer, que emana do real pulsional e

8 Não há representação d'A Mulher no inconsciente, daí Lacan afirmar que A Mulher não existe, marcando-a com uma barra: $\mathbb{A}$ mulher. 
marca a estrutura da fantasia, torna-se a responsável por ancorar a teoria sexual de que todos têm pênis. Até o momento da diferenciação dos sexos, meninos e meninas participam igualmente da norma fálica, primado que permitirá a articulação da castração do Outro materno como ponto nodal entre a sexualidade e a subjetivação da falta, por onde se distinguem os caminhos do Édipo nos homens e nas mulheres: se, em um primeiro momento, há a universalidade do falo, em um segundo essa ilusão cai a partir da percepção da falta no campo materno, para que em um terceiro essa falta possa ser simbolizada pelo próprio sujeito a partir da ameaça ou da constatação da perda. Nesse contexto, lendo Freud com Lacan, a significação da castração se apresentará por retroação. Trata-se de uma operação simbólica, metafórica, cujo objeto é imaginário - o falo —, conferindo significação aos objetos como destacáveis, capazes de gerar, como consequência:

A representação de um dano narcísico, por perda corporal, como na perda do seio materno após mamar, no cotidiano depósito das fezes, e até mesmo na separação do ventre da mãe ao nascer. Contudo, só cabe falarmos de um complexo de castração quando essa representação de uma perda for associada com os genitais masculinos. (Freud, 1923/2012, pp. 147-148)

Decerto que a dicotomia ter ou não ter o pênis — ou seja, ter ou não ter o suporte imaginário do falo - trouxe ao campo psicanalítico as mais diversas questões. No entanto, é justamente por que a primazia fálica antecede a percepção da presença ou da ausência do pênis que a castração do agente materno pode ser simbolizada como incompletude do Outro, por onde o sujeito vem significar sua própria falta no registro sexual, buscando um efeito de sentido. Esse é o ponto-chave na subjetivação sexuada, uma falta real - inerente ao ser de linguagem - que busca apoio no corpo - atrelado aos campos imaginário e simbólico - e visa à produção de sentido - pura aparência, que não elimina as questões sobre o sexo que abarcam o humano. Se estivéssemos referidos unicamente ao aspecto anatômico, nada faltaria ao campo materno, uma vez que o corpo é apenas diferente nos dois sexos, anatomicamente distinto no homem e na mulher. É por isso que Lacan destaca e insiste na existência de um único significante da sexuação, o falo, que marca, em nível inconsciente, que o Outro sexuado não existe. Não foi à toa que Freud o postulou no centro da partilha dos sexos, do que resulta a significação fálicos X castrados, na qual se articula a subjetivação sexuada, ou, como intitula seu texto, por onde se dão as consequências psíquicas da distinção anatômica dos sexos (Freud, 1925/2012), apontando que a anatomia não é capaz de proteger o sujeito da questão do desejo do Outro. O falo, significante da falta, embora possa apoiar-se na imagem corporal, possibilitando ao ser sexuado, pela via do discurso, o acesso à aparência, jamais se reduzirá a ela. Che vuoi? Essa é a questão em torno da qual o sujeito, referido ao Outro, como marca da alteridade, 
tenta ancorar a resposta sobre seu próprio sexo. Logo, ser homem ou ser mulher não é uma questão anatômica, mas uma escolha do sujeito, uma escolha inconsciente do sexo diante dos efeitos corpóreos produzidos pela incorporação do simbólico, marca que produz sua forma para além de qualquer silhueta a ser refeita cirurgicamente, para além de qualquer transplante ou remoção do sexo.

\section{Considerações finais}

$\mathrm{Na}$ aspiração do que é ser homem ou do que é ser mulher, uma vez que o falo é o obstáculo para alcançar o Outro sexo - que escapa à linguagem, mantém-se no registro do real e impossibilita a significação das funções sexuais -, resta ao homem parecer tê-lo, puro semblante pelo qual tenta proteger-se da falta, e às mulheres, parecer sê-lo, semblante de objeto como recurso ao desejo do Outro. Aqui, a função operativa do pênis, suporte imaginário do falo, vem funcionar para o ser de linguagem como o objeto do desejo no nível do ter, uma vez que é o único órgão do corpo capaz de orientá-lo: desejo confesso com a ereção e ausente com a detumescência. Diferente das mulheres, que são não-todas em seu corpo como seres sexuados, os homens se apoiam no corpo; corpo esse agitado pela linguagem, no qual a angústia, como efeito da ameaça de castração, só se faz presente devido à privilegiada relação que os homens têm com o órgão viril. Freud já havia salientado o narcisismo do órgão (Freud, 1927/2011) ao referir-se à angústia de castração que incide nos meninos sem qualquer relação com uma ameaça real, advinda do exterior. $O$ fato de o menino amar seu pênis desde as primeiras ereções é o que enraíza o temor de sua perda. Já para as meninas, há uma constatação da falta, ferida na imagem do corpo que produz o Penisneid e a consequente angústia de perda do amor, "porque a própria menina se considera, nem que seja por um momento, castrada, na acepção de privada do falo, e castrada pela operação de alguém, que primeiramente é sua mãe, ponto importante (...)" (Lacan, 1958/1998, p. 687).

É assim que o órgão ganha uma importância prevalente para o parlêtre, na qual se evidencia que a diferença anatômica é, antes, uma diferença significante referida à lógica do ter. Amarrada à fantasia, a lógica do ter torna-se uma estratégia, modo pelo qual o homem tenta suprir a relação sexual que não existe, por onde espera que o(a) parceiro(a) venha lhe restituir a falta marcada pela castração, sendo o falo que lhe falta e que lhe dará acesso ao gozo, uma vez que:

A angústia do homem liga-se à possibilidade do não poder. Daí o mito, bastante masculino, que faz da mulher o equivalente de uma de suas costelas. Essa costela lhe foi retirada, não se sabe qual, e, por outro lado, não lhe falta nenhuma. Mas está claro que, no mito da costela, trata-se justamente desse objeto perdido. (Lacan, 1962-1963/2005, p. 209) 
Percebamos, portanto, que “(...) a função fálica não impede os homens de serem homossexuais. Mas é ela também que lhes serve para se situarem como homens (...)" (Lacan, 1972-1973/1985, p. 97). Dito de outro modo, o fato é que, para os homens, sejam eles homo ou heterossexuais, não há a menor chance de gozarem do corpo do Outro, o que não impede que possam desejar de todas as maneiras; uma vez que embaixo da roupa do parceiro sexual só há um resto, que chamamos de objeto $a$. Assim, ao lermos Freud com Lacan, podemos constatar que o homem é todo edípico; tudo passa pela castração, nada escapa à Lei do pai, sendo impossível acessar esse resto que fica fora da castração no Édipo feminino. No entanto, o que importa percebermos é que isso não impede que ele se utilize do semblante feminino, fazendo-se de objeto a para o Outro. O semblante é o único destino possível aos seres falantes. Contudo, por mais que um homem se utilize do semblante feminino $-a-$, como homem, de todo inscrito na lógica do ter, seu gozo mantém-se submetido ao gozo fálico, ao gozo castrado, fantasístico, mesmo que escolha feminilizar-se, ocupando o lugar de a para alguém. Daí o homem não ser mais que um significante, já que o $\Phi$, ao dar suporte do lado masculino, também simboliza seu fracasso, “(..) porque, onde ele [o homem] entra em jogo como significante, ele só entra quoad castrationem, quer dizer, enquanto tendo relação com o gozo fálico" (Lacan, 1972-1973/1985, pp. 49-50), impossibilidade real pela qual a fantasia se articula como proibição edípica advinda de uma ameaça, mantendo viva a crença na relação sexual.

Às mulheres, justamente por serem não-todas, o falo não lhes é indiferente, $\mathrm{e}$ é desse ponto que Lacan dá um novo passo em contraponto à logica do ter: ser o falo. Embora não haja essência de ser para o ser de linguagem, é pela via de ser o falo simbólico, o falo como falta, que as mulheres despertam o desejo, transformam-se naquilo que não têm, sendo o objeto de desejo do Outro. Por isso, Lacan afirma que as mulheres são conciliadoras, cada uma com seu cada um, são capazes de fazer ilimitadas concessões, prestando-se à perversão ${ }^{9}$ do parceiro:

O que a conduz à mascarada que se conhece e que não é mentira que os ingratos, ao colocarem n'O homem, lhe imputam. Antes para-o-que-der-e-vier de preparar-se para que a fantasia d'O homem encontre nela sua hora da verdade. Isso não é exagero, pois a verdade já é mulher por não ser toda, não-toda a dizer-se, em todo caso. (Lacan, 1974/1993, p. 71)

Assim, a posição feminina vem apresentar-se como um recurso possível diante do Outro. Recorrer à mascara feminina é ser o falo que o Outro deseja, uma vez que, ao aderir ao impossível de ser, o semblante feminino revela a castração a

9 Trata-se da perversão polimorfa do macho. 
partir da identificação das mulheres com a falta-a-ter, denúncia da castração sem recobrimento da falta, próprio à posição sexuada das mulheres, capaz de revelar o semblante feminino por excelência. No entanto, em relação ao gozo, é importante sublinhar que, mesmo no lugar de causa para seu(ua) parceiro(a), no lugar de objeto $a$, resta-lhes o gozo fálico, marcado pela impossibilidade de fazer Um. Logo, ao se posicionarem como tendo ou sendo o falo, homens e mulheres tentam suprir a inexistência da relação sexual, mantendo-se na via do gozo fálico, por onde a incompatibilidade entre o ser e o ter reside.

Desse modo, o que os manuais diagnósticos pretendem com o dito transtorno do desenvolvimento sexual? O que curar do sexo? Diante das diversas questões aqui apontadas, não objetivamos qualquer fechamento ou conclusão, pelo contrário. Ao reservamos esta pesquisa à transexualidade e ao estranhamento do corpo, apontamos para o caráter enigmático da sexualidade e para o recurso da criação, saída diante do mal-estar. Assim, deixamos como questão: não seria a criação o recurso utilizado por todos os sujeitos, transexuais ou não, para a construção de seu sexo? Com Freud, sabemos que a sexualidade está na contramão do discurso hegemônico implantado pela cultura e, com Lacan, temos uma direção para pensarmos as diversidades sexuais: "Ora, signi- $\varphi$-que! Só quebrando o significante em sua letra damos conta dele” (Lacan, 1971-1972/2012, p. 17). Daí a psicanálise operar na exceção, na contramão da promessa de um bem comum a todos, com normas e princípios que excluem as diferenças. A psicanálise, ao sustentar um discurso ético, pautado pelo que há de mais singular e mais íntimo em cada sujeito, aponta o único caminho para o inconsciente, testemunho do desejo, que se sustenta na diferença absoluta, centrada no real.

\section{Referências bibliográficas}

American Psychiatric Association (APA). (1952). Diagnostic and statistical manual of mental disorders. Washington.

American Psychiatric Association (APA). (1968). Diagnostic and statistical manual of mental disorders: second edition. Washington.

American Psychiatric Association (APA). (1980). Diagnostic and statistical manual of mental disorders: third edition. Washington.

American Psychiatric Association (APA). (1994/1995). Manual diagnóstico e estatístico de transtornos mentais: DSM-4. Porto Alegre: Artmed.

American Psychiatric Association (APA). (2013/2014). Manual diagnóstico e estatístico de transtornos mentais: DSM-5. Porto Alegre: Artmed.

Brasil. Ministério da Saúde. (2008a). Portaria no 1.707, de 18 de agosto de 2008. Diário Oficial da União, seção 1, Brasília, DF, 19 ago. Obtido em 23 de abril de 2016. Recuperado de http://bvsms.saude.gov.br/bvs/saudelegis/gm/2008/ prt1707_18_08_2008.html 
Brasil. Ministério da Saúde. (2008b). Secretaria de Atenção à Saúde. Portaria no 457, de 19 de agosto de 2008. Diário Oficial da União, seção 1, Brasília, DF, 20 ago. Obtido em 23 de abril de 2016. Recuperado de http://bvsms.saude.gov.br/ bvs/saudelegis/sas/2008/prt0457_19_08_2008.html

Brasil. Ministério da Saúde. (2013). Portaria oㅡ 2.803, de 19 de novembro de 2013. Diário Oficial da União, seção 1, Brasília, DF, 21 nov. Obtido em 23 de abril de 2016. Recuperado de http://bvsms.saude.gov.br/bvs/saudelegis/gm/2013/ prt2803_19_11_2013.html

Freud, S. (1914/2012). Introdução ao narcisismo. (José Luis Etcheverry, Trad.). In J. Strachey (Ed.). Obras completas (Vol. 14, 2a. ed., pp. 65-98). Buenos Aires: Amorrortu.

Freud, S. (1923/2012). A organização genital infantil: uma interpolação na teoria da sexualidade. (José Luis Etcheverry, Trad.). In J. Strachey (Ed.). Obras completas (Vol. 19, 2a. ed., pp. 141-150). Buenos Aires: Amorrortu.

Freud, S. (1925/2012). Algumas consequências psíquicas da diferença anatômica entre os sexos. (José Luis Etcheverry, Trad.). In J. Strachey (Ed.). Obras completas (Vol. 19, 2a. ed., pp. 259-276). Buenos Aires: Amorrortu.

Freud, S. (1927/2011). Fetichismo. (José Luis Etcheverry, Trad.). In J. Strachey (Ed.). Obras completas (Vol. 21, 2a. ed., pp. 141-152). Buenos Aires: Amorrortu. Lacan, J. (1958/1998). A significação do falo. In J. Lacan. Escritos (pp. 692-703). (Vera Ribeiro, Trad.). Rio de Janeiro: Jorge Zahar.

Lacan, J. (1959-1960/1997). O seminário, livro 7: a ética da psicanálise. Rio de Janeiro: Jorge Zahar.

Lacan, J. (1962-1963/2005). O seminário, livro 10: a angústia. Rio de Janeiro: Jorge Zahar.

Lacan, J. (1964/1998). O seminário, livro 11: os quatro conceitos fundamentais da psicanálise. Rio de Janeiro: Jorge Zahar.

Lacan, J. (1971/2009). O seminário, livro 18: de um discurso que não fosse semblante. Rio de Janeiro: Jorge Zahar.

Lacan, J. (1971-1972/2012). O Seminário, livro 19: ...ou pior. Rio de Janeiro: Jorge Zahar.

Lacan, J. (1972-1973/1985). O seminário, livro 20: mais, ainda. Rio de Janeiro: Jorge Zahar.

Lacan, J. (1974/1993). Televisão. Rio de Janeiro: Jorge Zahar.

Lacan, J. (1974-1975). O seminário, livro 22: RSI. Inédito.

Lacan, J. (1975/1994). Resposta a uma pergunta de Marcel Ritter. In J. Lacan. Estudios de psicossomática. Buenos Aires: Atuel.

OMS. (1993). Classificação de transtornos mentais e de comportamento da CID-10: descrições clínicas e diretrizes diagnósticas. Porto Alegre: Artes Médicas. 
Soler, C. (2010). O corpo falante. In. D. Fingermann (Org.). Caderno de Stylus. Rio de Janeiro: Internacional dos Fóruns do Campo Lacaniano.

Recebido: 28/10/2017

Aprovado: 09/01/2018 
